\title{
OPTIMIZATION ALGORITHMS FOR RISK MANAGEMENT IN MULTIDIMENSIONAL GAUSSIAN SYSTEMS
}

\author{
A. A. Surina, South Ural State University, Chelyabinsk, Russian Federation, \\ surinaaa@susu.ru
}

\begin{abstract}
The paper presents a comparative analysis of optimization algorithms to solve the risk management problem in Gaussian stochastic systems. The optimization task considered in the work has a number of features that need to be taken into account in the solution. The features of the problem are the presence of a stochastic restriction on the required level of risk, the non-convexity of the area of admissible decisions and the increase in the number of control variables in the task of achieving an acceptable level of risk. There are proposed ways of solving the problem of the occurrence of a set of local minimums. The study of the effectiveness of the zero, first and second-order methods for solving the problem of unconditional minimization using the Monte Carlo statistical test method is carried out. Each method was adapted to the specifics of the problem being solved. The software implementation of all presented algorithms was performed. The article presents the results of the study. The computational complexity of algorithms is calculated.
\end{abstract}

Keywords: model; risk; control; stochastic system; algorithm; monitoring; optimization.

\section{Introduction}

The research on the safety of the complex stochastic systems is based on the theory of risk. In a broad sense, understand the possible danger of any failure as a risk. Real systems, as a rule, are multidimensional, it's functioning in many respects has stochastic character, and at them, it is often possible to allocate tens of different risk factors [1]. In the performance of a task of risk management, it is necessary to base on a risk model. Usually modeling a risk comes down to the selection of dangerous outcomes, the quantitative assignment of consequences from their occurrence and estimation of the probabilities of these outcomes [2-5]. For relatively simple objects when it is possible to specify a priori all dangerous outcomes, in the presence of statistical information or expert estimates on chances of their emergence, in general, this approach yields the results acceptable in practice $[6,7]$. However, for many complex systems, such as the economy, society, health, etc. to allocate all these dangerous outcomes is not possible [8].

In [9], an approach to risk modeling is proposed, according to which the stochastic system $S$ is represented as a random vector $\mathbf{X}$ with a certain probability density $p_{\mathbf{x}}(\mathbf{x})$ and mutually correlated components. The multidimensional risk model for Gaussian stochastic systems is described in [10]. In this case, the numerical characteristics are the covariance matrix $\boldsymbol{\Sigma}=\left\{\sigma_{i j}\right\}_{m \times m}$ and the expectation vector $\mathbf{a}=\left(a_{1}, a_{2}, . ., a_{m}\right)^{T}$ for the random vector of a Gaussian random vector $\mathbf{X}=\left(X_{1}, X_{2}, \ldots, X_{m}\right)$.

Risk management in the Gaussian system is described in more detail in [11]. One of the tasks proposed in [6] is considered: achieving an acceptable level of risk $r^{*}$ with minimal changes in the numerical characteristics $\boldsymbol{\Sigma}$ and $\mathbf{a}$ of the Gaussian system $\mathbf{X}_{0}$ :

$$
\left\{\begin{array}{l}
f(\mathbf{a}, \mathbf{\Sigma})=\sum_{j=1}^{m} \sum_{k=j}^{m}\left(\sigma_{j k}-\sigma_{j k}^{0}\right)^{2}+\sum_{i=1}^{m}\left(a_{i}-a_{i}^{0}\right)^{2} \rightarrow \min _{\mathbf{a}, \mathbf{\Sigma}}, \\
r(\mathbf{X}) \geq r^{*}, \mathbf{\Sigma} \in G_{\boldsymbol{\Sigma}}, \mathbf{a} \in H_{\mathbf{a}} .
\end{array}\right.
$$


Problem (1) is a nonlinear programming problem with a stochastic risk constraint. The numerical characteristics of the random vector $\mathbf{X}$ are used as control variables in (1).

For arbitrary applications, methods have not yet been developed to effectively solve them, which is primarily due to the direction of nonlinear programming methods to solve certain classes of optimization problems. At the same time, real problems differ both in dimension and in the nature of the problem itself. There may be difficulties with finding analytical expressions for more variables, as well as with the target function itself, which may be, for example, discontinuous or non-convex.

The purpose of this article is to study the problem of achieving an acceptable level of risk $r^{*}$ with minimal changes in the numerical characteristics $\boldsymbol{\Sigma}$ and $\mathbf{a}$ of the Gaussian system. It is also necessary to describe algorithms that allow to solve this problem by the most effective method, and taking into account the peculiarities of the problem.

One of such features is a stochastic restriction for the required level risk $r_{\operatorname{targ}} \geq r^{*}(\boldsymbol{\Sigma}, \mathbf{a})$. The second feature is the non-convexity of the area of permissible solutions. Another feature is the growth of a number of the operating variables in a problem of achievement of the acceptable risk level of $r^{*}$ with minimal changes in the numerical characteristics $\boldsymbol{\Sigma}$ and a of the Gaussian system with a quadratic rate: $m(m+3) / 2$.

Taken together, these features limit the use of standard algorithms for solving optimization problems. Therefore, it is necessary to develop new algorithms or modify (adapt) existing, well-known optimization algorithms for solving similar problems.

\section{Risk Management Model in Gaussian Stochastic Systems as an Optimization Problem}

The risk in (1) is described as [10]:

$$
r(X)=\iint_{R^{m}} \ldots \int g(\mathbf{x}) p_{\mathbf{x}}(\mathbf{x}) d \mathbf{x},
$$

where $g(\mathbf{x})$ is a function of consequences from dangerous situations (risk function). Varying $g(\mathbf{x})$ in (2) it is possible to receive various estimates of risk [4].

Problem (1) is an optimization problem and it is necessary to check how many local minimums the solution will have.

Since the function is convex, it is necessary to show that the set on which we are looking for a solution is also convex. Or prove the return.

Suppose that for a two-dimensional case, the set composed of constraints is convex. There are many ways to check this, the easiest way is to prove that the Hessian is positive.

For the two-dimensional case, problem (1) will take the form:

$$
\sum_{j=1}^{2} \sum_{k=j}^{2}\left(\sigma_{j k}-\sigma_{j k}^{0}\right)^{2}+\sum_{i=1}^{2}\left(a_{i}-a_{i}^{*}\right)^{2} \rightarrow \min _{\mathbf{a}, \boldsymbol{\Sigma}}
$$

at restrictions

$$
\left\{\begin{array}{l}
\sigma_{j j} \sigma_{k k}>\sigma_{j k}^{2}, \quad \sigma_{j k}=\sigma_{k j}, \quad \sigma_{j j}>0, \quad 1 \leq j, k \leq 2 \\
\sigma_{j k}^{-}<\sigma_{j k}<\sigma_{j k}^{+}, \quad 1 \leq j, k \leq 2 \\
a_{i}^{-}<a_{i}<a_{i}^{+}, \quad 1 \leq i \leq 2 \\
r_{\operatorname{targ}} \geq r^{*}(\boldsymbol{\Sigma}, \mathbf{a})+\varepsilon
\end{array}\right.
$$


The condition $r_{\operatorname{targ}} \geq r^{*}(\boldsymbol{\Sigma}, \mathbf{a})$ is stochastic, it is not checked.

$$
\left\{\begin{array}{l}
\sigma_{11} \sigma_{22}>\sigma_{12}^{2}, \sigma_{12}=\sigma_{21}, \sigma_{11}>0, \sigma_{22}>0 \\
\sigma_{12}^{-}<\sigma_{12}<\sigma_{12}^{+} \\
a_{1}^{-}<a_{1}<a_{1}^{+} \\
a_{2}^{-}<a_{2}<a_{2}^{+} .
\end{array}\right.
$$

Let 's check that the bulge condition is met for one of the constraints. As $\sigma_{12}^{2}=\sigma_{11} \sigma_{22} \rho_{12}^{2}$ then $\sigma_{11} \sigma_{22}>\sigma_{11} \sigma_{22} \rho_{12}^{2}$ or $\sigma_{11} \sigma_{22}-\sigma_{11} \sigma_{22} \rho_{12}^{2}>0$. Find the second derivatives for $z=\sigma_{11} \sigma_{22}-\sigma_{11} \sigma_{22} \rho_{12}^{2}>0$ :

$$
\begin{gathered}
z_{\sigma_{1}}^{\prime}=2 \sigma_{1} \sigma_{22}-2 \sigma_{1} \sigma_{22} \rho_{12}^{2}, \\
z_{\sigma_{2}}^{\prime}=2 \sigma_{11} \sigma_{2}-2 \sigma_{11} \sigma_{2} \rho_{12}^{2}, \\
z_{\sigma_{1} \sigma_{1}}^{\prime \prime}=2 \sigma_{22}-2 \sigma_{22} \rho_{12}^{2}, \\
z_{\sigma 2 \sigma_{21}}^{\prime \prime}=2 \sigma_{11}-2 \sigma_{11} \rho_{12}^{2}, \\
z_{\sigma_{1} \sigma_{2}}^{\prime \prime}=4 \sigma_{1} \sigma_{2}-4 \sigma_{1} \sigma_{2} \rho_{12}^{2} .
\end{gathered}
$$

The Hesse matrix will then take the form:

$$
H=\left(\begin{array}{cc}
2 \sigma_{22}\left(1-\rho_{12}^{2}\right) & -4 \sigma_{1} \sigma_{2}\left(1-\rho_{12}^{2}\right) \\
-4 \sigma_{1} \sigma_{2}\left(1-\rho_{12}^{2}\right) & 2 \sigma_{11}\left(1-\rho_{12}^{2}\right)
\end{array}\right) .
$$

Find the eigenvalues of the matrix:

$$
\begin{gathered}
\triangle_{1}=2 \sigma_{22}\left(1-\rho_{12}^{2}\right), \\
\triangle_{2}=-12 \sigma_{1} \sigma_{2}\left(1-\rho_{12}^{2}\right) .
\end{gathered}
$$

The eigenvalues were obtained with different signs. Thus, the Hesse matrix of the function $\mathrm{z}$ is negatively defined, and therefore $z=\sigma_{11} \sigma_{22}-\sigma_{11} \sigma_{22} \rho_{12}^{2}>0$ is a non-convex function.

Hence, we conclude that the set is not convex either. This means that problem (1) may have a set of local minimums.

In addition, in a problem (1) the risk needs to be estimated in each received point of the area of admissible decisions, that is the constraint $r_{\operatorname{targ}} \geq r^{*}(\boldsymbol{\Sigma}, \mathbf{a})$ is stochastic.

\section{Algorithm of the Barrier Function Method}

Previously, a description of the risk management algorithm in Gaussian systems based on the barrier function method was given [11].

We will describe the algorithm of the barrier function method in more detail.

To begin with, you must set the risk value $r_{\text {targ }}$ that must be achieved when solving the conditional minimization problem. The ideal point is then selected. Note that the solution to the problem (1) is only found when the initial risk value is higher than the target risk value $r_{\text {targ. }}$. In this case, the risk can be reduced, otherwise, you can worsen the values of the numerical characteristics and the value of the risk itself.

Step 1. Let's set initial values of elements of the covariance matrix $\Sigma_{0}$ and the expectations vector of $\mathbf{a}_{0}, b_{k} \geq 0, C>1, \varepsilon>0, r_{\text {targ }}$. 
Step 2. Let's make support function

$$
F\left(\boldsymbol{\Sigma}, \mathbf{a}, b_{k}\right)=f(\boldsymbol{\Sigma}, \mathbf{a})+P\left(\boldsymbol{\Sigma}, \mathbf{a}, b_{k}\right),
$$

where $P\left(\boldsymbol{\Sigma}, \mathbf{a}, b_{k}\right)$ - penalty function, $F\left(\boldsymbol{\Sigma}, \mathbf{a}, b_{k}\right)$ - support function.

The inverse function is selected as a penalty function: $P\left(\boldsymbol{\Sigma}, \mathbf{a}, b_{k}\right)=b_{k} \sum_{j=1}^{m} \frac{1}{t_{j}(\boldsymbol{\Sigma}, \mathbf{a})}$, where $b_{k}$ - the positive value chosen randomly.

Then taking into account all restrictions the support function will take the form:

$$
\begin{aligned}
& F\left(\boldsymbol{\Sigma}, \mathbf{a}, b_{k}\right)=\sum_{j=1}^{m} \sum_{k=j}^{m}\left(\sigma_{j k}-\sigma_{j k}^{0}\right)^{2}+\sum_{i=1}^{m}\left(a_{i}-a_{i}^{0}\right)^{2}+b^{k} \cdot\left(\sum_{j=1}^{m} \frac{1}{\sigma_{j j}}+\right. \\
& +\sum_{j=1}^{m} \sum_{k=j}^{m} \frac{1}{\sigma_{j j} \sigma_{k k}-\sigma_{j k}^{2}}+\sum_{j=1}^{m} \sum_{k=j}^{m} \frac{1}{\sigma_{j k}^{-}-\sigma_{j k}}+\sum_{j=1}^{m} \sum_{k=j}^{m} \frac{1}{\sigma_{j k}-\sigma_{j k}^{+}}+ \\
& \left.+\sum_{i=1}^{m} \frac{1}{a_{i}^{-}-a_{i}}+\sum_{i=1}^{m} \frac{1}{a_{i}-a_{j}^{+}}\right) .
\end{aligned}
$$

Step 3. Let's find minimum point $\mathbf{x}_{k}$ of the function $F\left(\boldsymbol{\Sigma}, \mathbf{a}, b_{k}\right)$ by means of the unconstrained optimization method based on the Nelder-Mead method [12] (see Fig. 1).

Step 4. Let's check the fulfillment of the condition of the end:

a) if $\left|P\left(\boldsymbol{\Sigma}^{k}, \mathbf{a}^{k}\right)-r^{*}\left(\boldsymbol{\Sigma}^{*}, \mathbf{a}^{*}\right)\right| \leq \varepsilon$, process of searching is completed: $\boldsymbol{\Sigma}^{k}=\boldsymbol{\Sigma}^{*}, \mathbf{a}^{k}=$ $\mathbf{a}^{*}, r\left(\Sigma^{k}, \mathbf{a}^{k}\right)=r^{*}\left(\Sigma^{*}, \mathbf{a}^{*}\right)$

b) if $\left|P\left(\Sigma^{k}, \mathbf{a}^{k}\right)-r^{*}\left(\Sigma^{*}, \mathbf{a}^{*}\right)\right| \geq \varepsilon$, put $b_{k+1}=\frac{b_{k}}{C}, \boldsymbol{\Sigma}^{k+1}=\boldsymbol{\Sigma}^{*}, \mathbf{a}^{k+1}=\mathbf{a}^{*}, k=k+1$, and proceed to step 2 .

We do not include the condition $r_{\operatorname{targ}} \geq r^{*}(\boldsymbol{\Sigma}, \mathbf{a})$ in the penalty function because of the risk function $r^{*}\left(\boldsymbol{\Sigma}^{*}, \mathbf{a}^{*}\right)$ is an implicit function and is not calculated analytically. Figure 1 shows that this condition is checked separately.

The algorithm of the method of unconstrained optimization based on the method of a deformable polyhedron is shown in Figure 2.

Feature of the solution of problem (1) by the barrier function method is the dependence of the choice of the initial point for the solution of a problem of unconstrained optimization from camber of area of admissible values of $\hat{D}$.

The Init2 function searches for the ideal point $\mathbf{x}_{\text {ideal }}$ and vertices of a polyhedron. The point at which the values of the elements of the covariance matrix $\boldsymbol{\Sigma}$ are close to or equal to zero, and the values of the expectation vector $\mathbf{a}$ - the best values specified earlier is chosen as the ideal point of the ideal. Changing values of the elements of $\boldsymbol{\Sigma}, \mathbf{a}$ and, calculating value $r^{*}$, at some moment the value of the probability of $r^{*}$ becomes equal $r_{\text {targ }}$. Infinitude number of such sets of values of the elements $\boldsymbol{\Sigma}$ and $\mathbf{a}$ form $m$-dimensional convex figure on which surface probability is equal $r_{\text {targ }}$. In the center of a figure the point $\mathbf{x}_{\text {ideal }}$ with probability $r_{\text {ideal }}=0$.

The BWPoint function carries out calculation of weight coefficients of points to find minimum and maximum values. Then the "best" point of $\mathbf{x}^{l}$ and "worst" $\mathbf{x}^{h}$ points where $F\left(x^{l}\right)=\min _{k=1, \ldots, m+1} F\left(x^{k}\right)$ and $F\left(x^{h}\right)=\max _{k=1, \ldots, m+1} F\left(x^{k}\right)$, and also the point of $\mathbf{x}^{s}$ in which the second largest is reached after maximal value of function is chosen. 
A. A. Surina

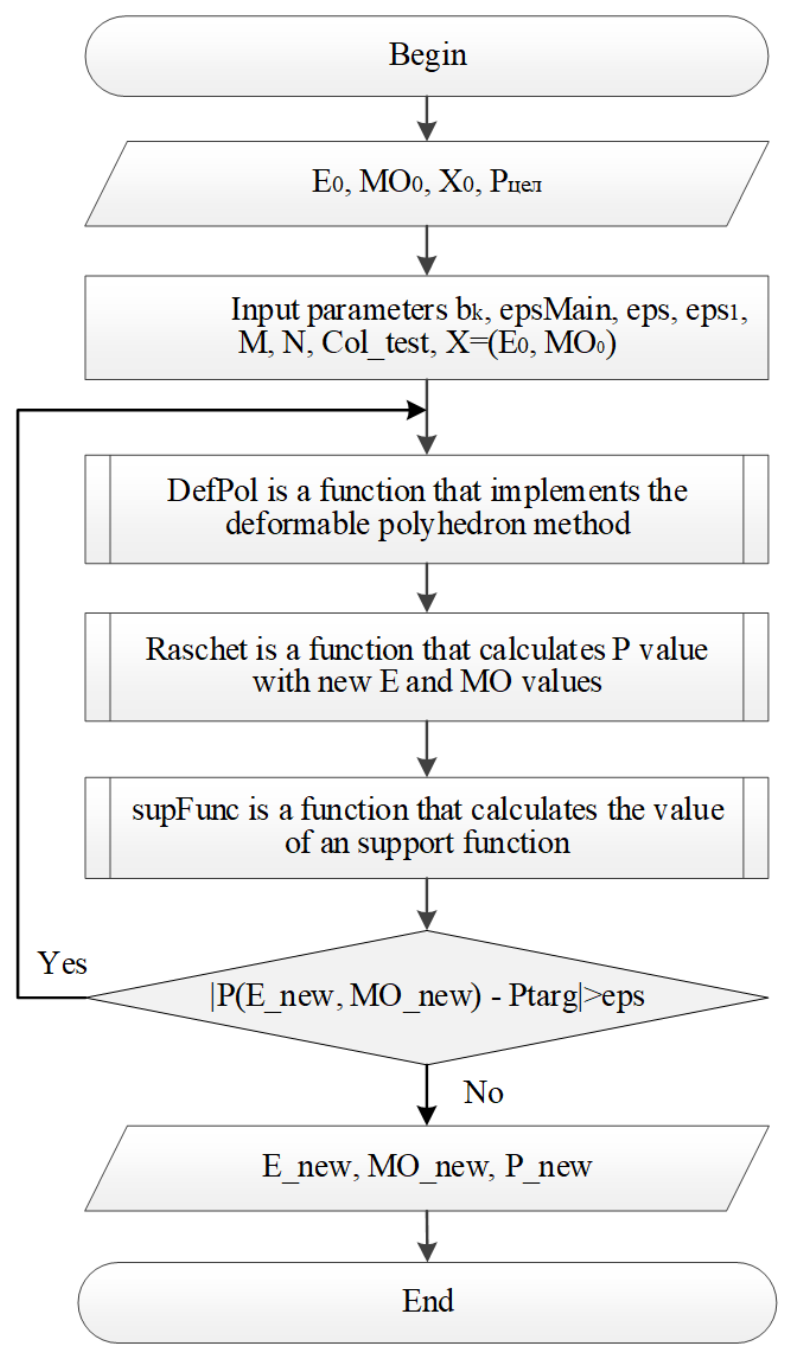

Fig. 1. The block diagram of the algorithm of the barrier function method.

The gravCenter function finds "barycenter" of all vertices of a polyhedron except for the "worst" $\mathbf{x}^{h}$ :

$$
x^{m+2}=\frac{1}{m+1}\left(\sum_{k=1}^{m+2} x^{k}-x^{h}\right)=\frac{1}{m+1} \sum_{k=1, k \neq h}^{m+2} x^{k} .
$$

The wReflect function carries out operation of reflection of the "worst" vertex $\mathbf{x}^{h}$ through the barycenter $x^{m+2}: x^{m+3}=x^{m+2}-x^{h}$. Let's receive the vector $x^{k}=x^{m+3}-x^{m+2}$. Otherwise the algorithm leaves the DefPol procedure, having kept the found values.

The wReplace function carries out the operation of replacement of vertices in case

$$
\theta=\left\{\frac{1}{m+1} \sum_{k=1}^{m+2}\left[F\left(x^{k}\right)-F\left(x^{m+2}\right)\right]^{2}\right\}^{\frac{1}{2}}>\varepsilon .
$$

After the values satisfying (1) have been found, the stochastic constraint on the required risk is checked. If the found values meet a condition, then the algorithm finishes 


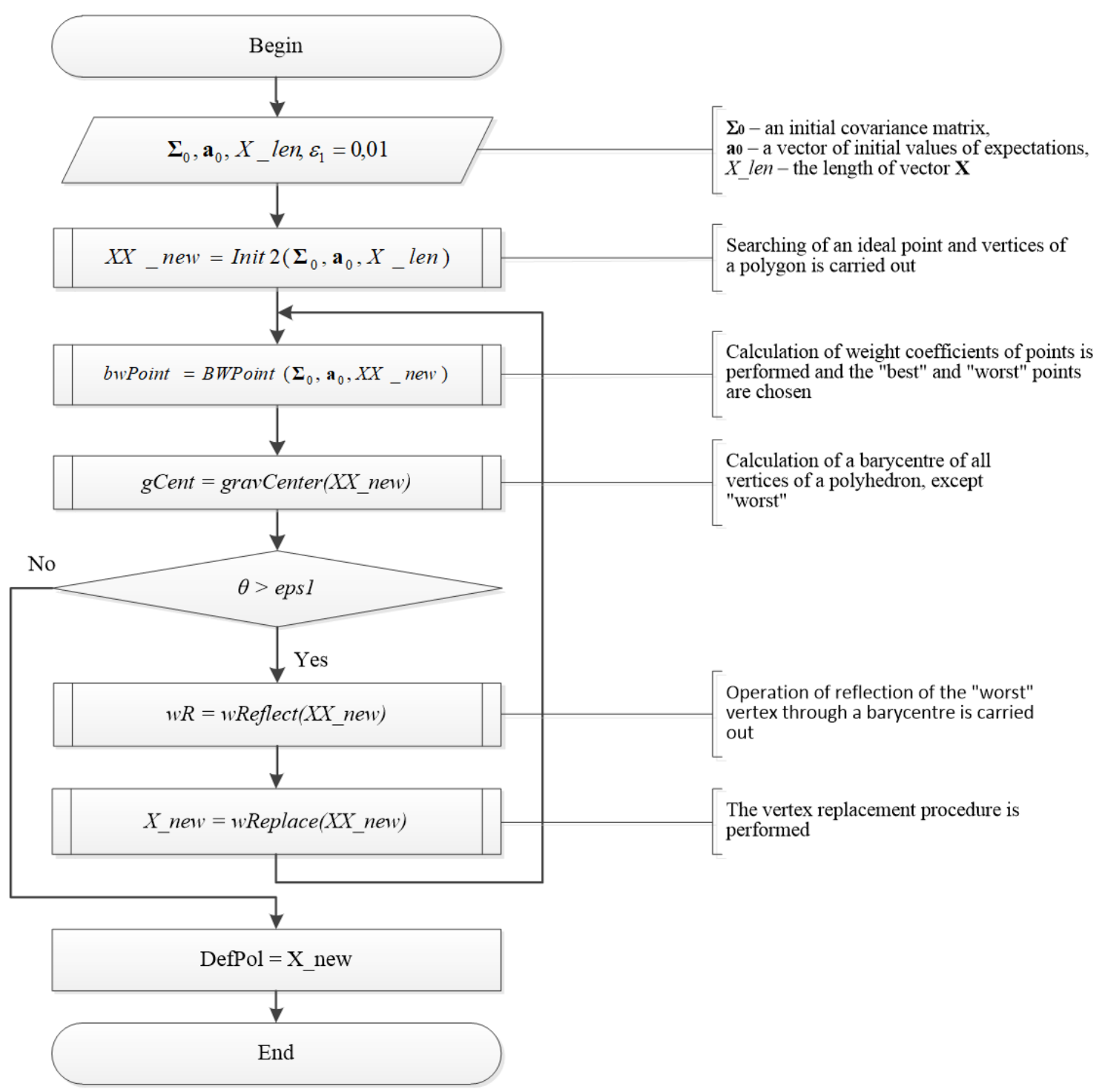

Fig. 2. The block diagram of the DefPol procedure for the modified method of the deformable polyhedron.

work and removes results. Otherwise, the method of barrier functions starts the work anew.

Also, in [11], the efficiency and accuracy of the algorithm were investigated.

\section{Comparative Analysis of Methods}

However, in addition to investigating the operability of the algorithm and its accuracy, it is also necessary to carry out a comparative analysis of the zero, first and second-order methods for unconstrained minimization.

As mentioned above, the problem of achieving acceptable risk $r^{*}(1)$ is an optimization problem with restrictions and is solved by the penalty function method. However, for the solution of a problem of unconstrained minimization modification of the Nelder-Mead method was offered, and as a result, there is a question of applicability of other methods 
for the solution to the problem without restrictions. Due to the non-convexity of the set of admissible decisions, it is necessary to analyze and compare the zero, first and second-order methods.

From the zero-order methods, a proposed modification of the Nelder-Mead method, the random search method with the return for a failed step, and the Hooke-Jeeves method were chosen; of the first-order methods is the constant-pitch gradient descent method; of the second-order methods is Newton's method [14].

It should also be mentioned that none of the zero-order methods in the "pure" form can be used to solve the problem (1) due to stochastic risk restriction. Therefore, each method is subject to adaptation and modification (as in the case of the Nelder-Mead method proposed in [11]).

Let's consider the algorithm of the Hooke-Jeeves method, which is used in the work for comparative analysis.

The ideal $\mathbf{x}_{\text {ideal }}$ point is chosen in the same manner as described above in the NelderMead method.

The initial point of search $\bar{x}^{0}$ is selected on a surface $m$-dimensional a convex figure. Then we set initial increment (step) of $\triangle \bar{x}^{0}$. Then we take a trial step on the variable $\mathrm{x}_{1}$, i.e. we define the next point of $\mathrm{x}_{1}^{0}+\Delta \mathrm{x}_{1}^{0}$. If the value of probability in this point became excellent от $r_{\text {targ }} \geq r^{*}\left(\boldsymbol{\Sigma}^{*}, \mathbf{a}^{*}\right)$, then from a $\mathbf{x}_{\text {ideal }}$ point $\mathbf{x}_{\text {ideal }}$ through $\mathrm{x}_{1}^{0}+\Delta \mathrm{x}_{1}^{0}$, we draw a vector and look for an intersection point of this vector with the surface of an $m$-dimensional convex figure where $r_{\text {targ }} \geq r^{*}\left(\boldsymbol{\Sigma}^{*}, \mathbf{a}^{*}\right)$.

We calculate the value of the target function in a point $\overline{x^{\prime}}=\left(x_{1}^{0}+\Delta x_{1}^{0}, x_{2}^{0}, \ldots, x_{n}^{0}\right)$. If the value of the function in this point is more than the value of function $f\left(\bar{x}^{0}\right)$, then we take a trial step on the same variable but in the direction, opposite to initial.

If the value of the function in a point $\overline{x^{\prime \prime}}=\left(x_{1}^{0}-\Delta x_{1}^{0}, x_{2}^{0}, \ldots, x_{n}^{0}\right)$ it is more than $f\left(\bar{x}^{0}\right)$, then we leave a point of $x_{1}^{0}$ unchanged. Otherwise, we replace the point $x_{1}^{0}$ with $\overline{x^{\prime}}$ or with $\overline{x^{\prime \prime}}$ depending on where the function value turned out less than the initial one.

Next, from the received point, we make trial steps for the remaining coordinates. In this case, we use the same algorithm as before. If the algorithm fails to take any successful steps, then reduce $\triangle \bar{x}$ again, we are looking for a point where the value of the target function will be less than the original one.

If at least one step was successful, then getting a point $\bar{x}^{01}$, it is necessary to minimize the target function by solving the problem

$$
\min _{\lambda} f\left(\bar{x}^{0}+\lambda \cdot\left(\bar{x}^{01}-\bar{x}^{0}\right)\right),
$$

in the direction of decreasing the function $-\bar{x}^{01}-\bar{x}^{0}$.

Here, the step value for each variable will be proportional to the step value at the stage of searching for the desired point.

If the step is successful, will get a new approximation at the minimization stage of the function $\bar{x}^{1}=\bar{x}^{0}+\lambda \cdot\left(\bar{x}^{01}-\bar{x}^{0}\right)$, где

$$
\lambda^{0}=\arg \min _{\lambda} f\left(\bar{x}^{0}+\lambda \cdot\left(\bar{x}^{01}-\bar{x}^{0}\right)\right) .
$$

And then we start a new exploratory search from the point $\bar{x}^{1}$. The algorithm continues until it reaches the minimum of the function [13]. 
As can be seen from the description of the algorithm, the method was adapted to the task of reaching an acceptable risk level with minimal changes in the numerical characteristics $\boldsymbol{\Sigma}$ и а.

Also, the random search method with the return for a failed step was adapted for this task. Let's describe the algorithm of this method.

Choosing the ideal point $\mathbf{x}_{\text {ideal }}$. Then set the starting point $x^{0}$. Each next point is found by the formula $x^{k+1}=x^{k}+t_{k} \cdot \xi^{k}$, where $t_{k}>0$ - step size; $\xi^{k}$ - random vector of unit length, determining the search direction, $k$ - iterations number. By generating random vectors $\xi^{k}$ algorithm get points that lie on the hypersurface of the radius $t_{k}$ centered at a point $x^{k}$. If the probability value at this point is different from $r_{t a r g} \geq r^{*}\left(\boldsymbol{\Sigma}^{*}, \mathbf{a}^{*}\right)$, then from the point, $\mathbf{x}_{\text {ideal }}$ через through the point $x_{1}^{0}+\Delta x_{1}^{0}$ draw a vector and look for the intersection point of this vector with the surface of an $m$-dimensional convex shape, where $r_{\text {targ }} \geq r^{*}\left(\boldsymbol{\Sigma}^{*}, \mathbf{a}^{*}\right)$. Calculate the value of the target function at the received point. If the received value has not decreased, then the step is considered unsuccessful and we return to the current center. The search continues. If the number of failed steps from point $x^{k}$ becomes equal to the specified number of iterations, then we continue the search from the same point, but before reducing the step. The search continues until the step is less than the specified value [14].

If the target function value in the found point is less than in the initial one, then we consider the step successful and continue the search from this point.

\section{Computational Experiment}

To compare zero-order methods, computational experiments were performed on a large amount of data generated using the Monte Carlo simulation for the number of risk factors $m=2,3,4$ [15].

Empirically, parameters for solving task (1) using barrier functions were selected: $b^{k}=1, C>1, \varepsilon_{1}=0,05$.

We will compare the efficiency of the selected methods based on these parameters for the task (1). Each method was applied to a number of risk factors $m=2,3,4$. The sample size $M$ was equal to 1000 . The number of tests that were performed for each method - col $=80$.

The obtained comparative characteristics of the results of the algorithms are presented in Tables 1-2.

Table 1

The minimum value of the target function

\begin{tabular}{|c|l|l|l|}
\hline \multirow{2}{*}{ Dimension } & \multicolumn{3}{|c|}{ The minimum value of the target function } \\
\cline { 2 - 4 } & $\begin{array}{l}\text { Modification of the } \\
\text { Nelder-Mead method }\end{array}$ & $\begin{array}{l}\text { Hooke-Jeeves } \\
\text { method }\end{array}$ & $\begin{array}{l}\text { The random search } \\
\text { method with the } \\
\text { return for a failed step }\end{array}$ \\
\hline 2 & 0.0517 & 0.1583 & 2.9183 \\
\hline 3 & 0.2259 & 0.6485 & 9.2951 \\
\hline 4 & 0.7923 & 1.0361 & 12.9121 \\
\hline
\end{tabular}


Table 2

Average calculation time in seconds

\begin{tabular}{|c|l|l|l|}
\hline \multirow{2}{*}{ Dimension } & \multicolumn{3}{|c|}{ Average calculation time, seconds } \\
\cline { 2 - 4 } & $\begin{array}{l}\text { Modification of the } \\
\text { Nelder-Mead method }\end{array}$ & $\begin{array}{l}\text { Hooke-Jeeves } \\
\text { method }\end{array}$ & $\begin{array}{l}\text { The random search } \\
\text { method with the } \\
\text { return for a failed step }\end{array}$ \\
\hline 2 & 8.05 & 11.36 & 37.17 \\
\hline 3 & 28.96 & 31.33 & 79.28 \\
\hline 4 & 107.03 & 95.18 & 152.32 \\
\hline
\end{tabular}

Analysis of obtained data during computational experiments showed that the modified Nelder-Mead method works faster than the other two zero-order methods. However, with the increase in the number of risk factors, the algorithm of the method begins to work slower, which is most likely due to the non-convexity of the area.

Figures 3-5 show the confidence intervals of the target function values.

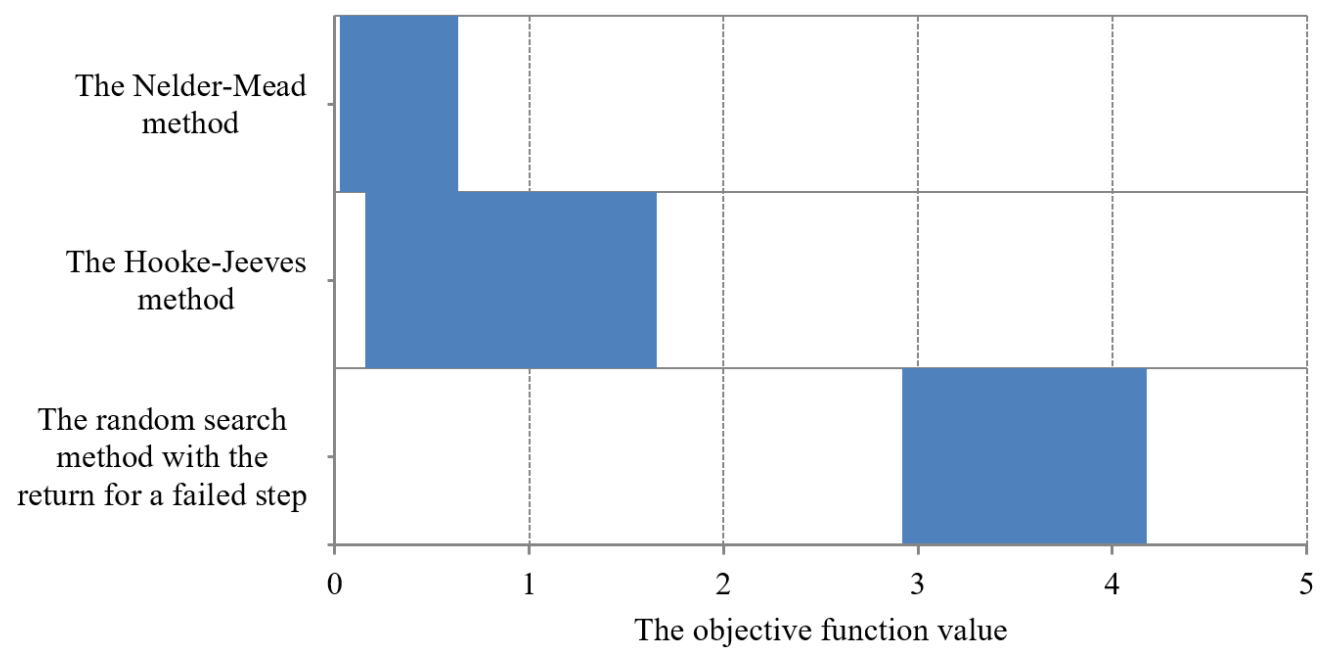

Fig. 3. Confidence interval of target function values for $m=2$ risk factors.

The values of the target function obtained in the search optimization process by the Hooke-Jeeves algorithm speak in favor of the Nelder-Mead method, but this gain decreases when the dimension increases. But it is necessary to take into account the more significant computational costs of calculating the vertices from which the algorithm makes the first кstepњ.

Analysis of the graphs showed that the range obtained during the calculation may indicate that the points obtained are different, which means the minimum point is not global.

How could such a large range have been obtained?

In some cases, the algorithm "descends" to the wrong minimum. This happens because the starting point was selected on the border of a non-convex area. Alternatively, lowering to a minimum from the starting point was performed in the direction of the non-convex area. 


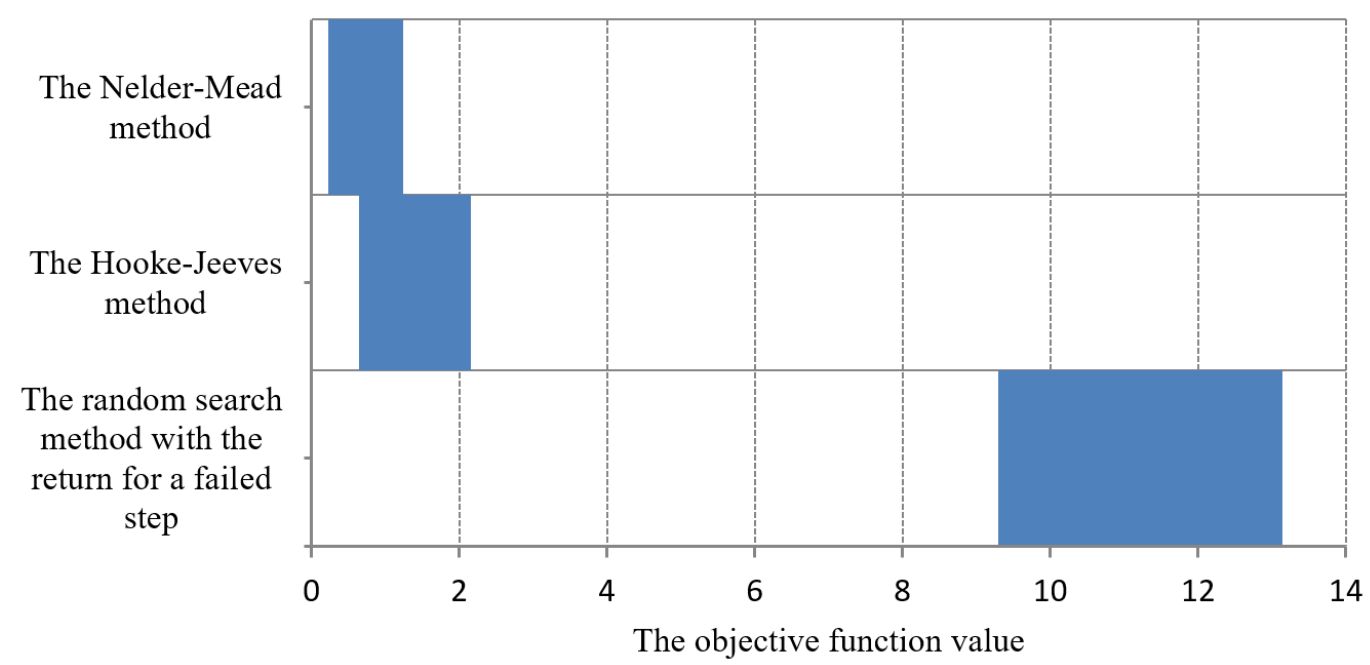

Fig. 4. Confidence interval of target function values for $m=3$ risk factors.

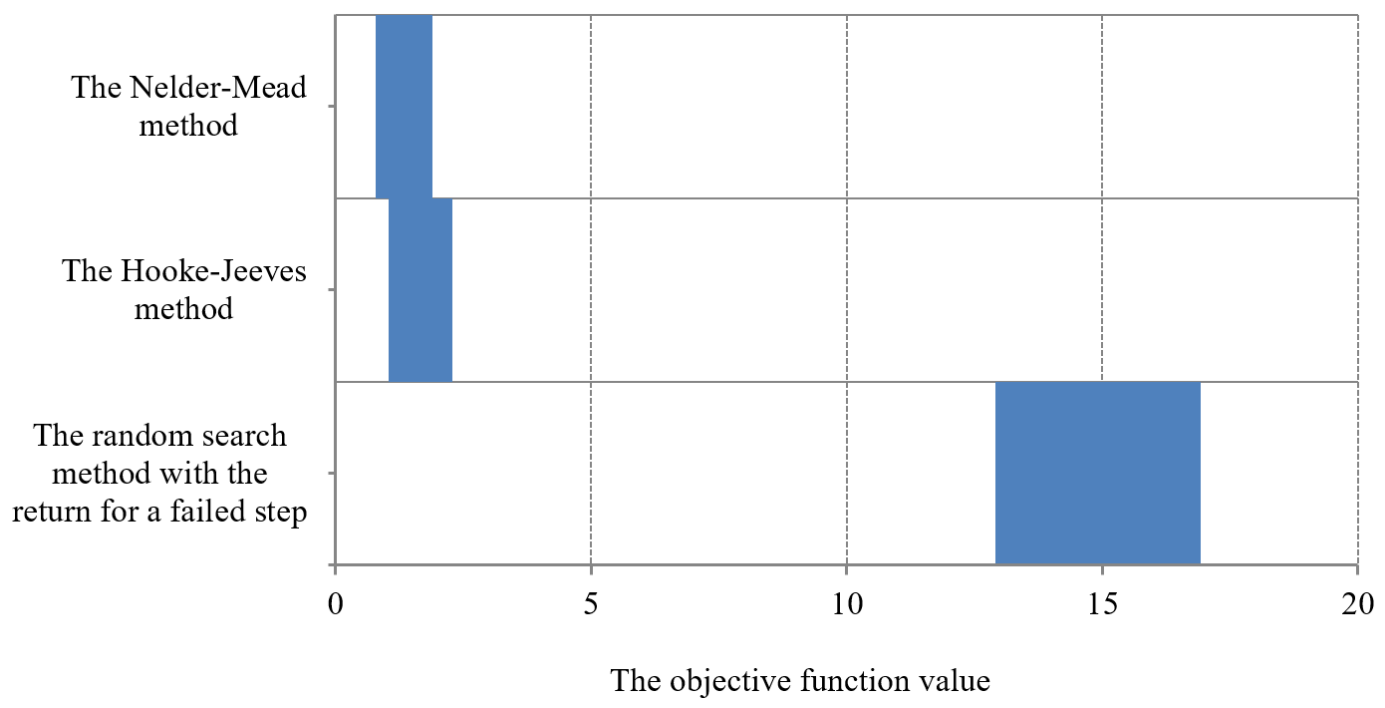

Fig. 5. Confidence interval of target function values for $m=4$ risk factors.

To avoid such inconsistencies, you can use multi-criteria optimization methods, such as the grid method.

Another solution to this problem is to limit the range of allowed values to a smaller range. This is possible if you have information about the location of the start point. However, this approach requires further research.

\section{Computational Complexity of an Algorithm}

When trying to use first and second-order methods to minimize, it was found that their application was associated with large computational difficulties. As the dimension increases, the number of operations performing function minimization is sharply grown. And since it is necessary to calculate also derivatives, the complexity increases even more.

Consider, in the example of $m=2$ risk factors, solving the problem (1) of achieving an 


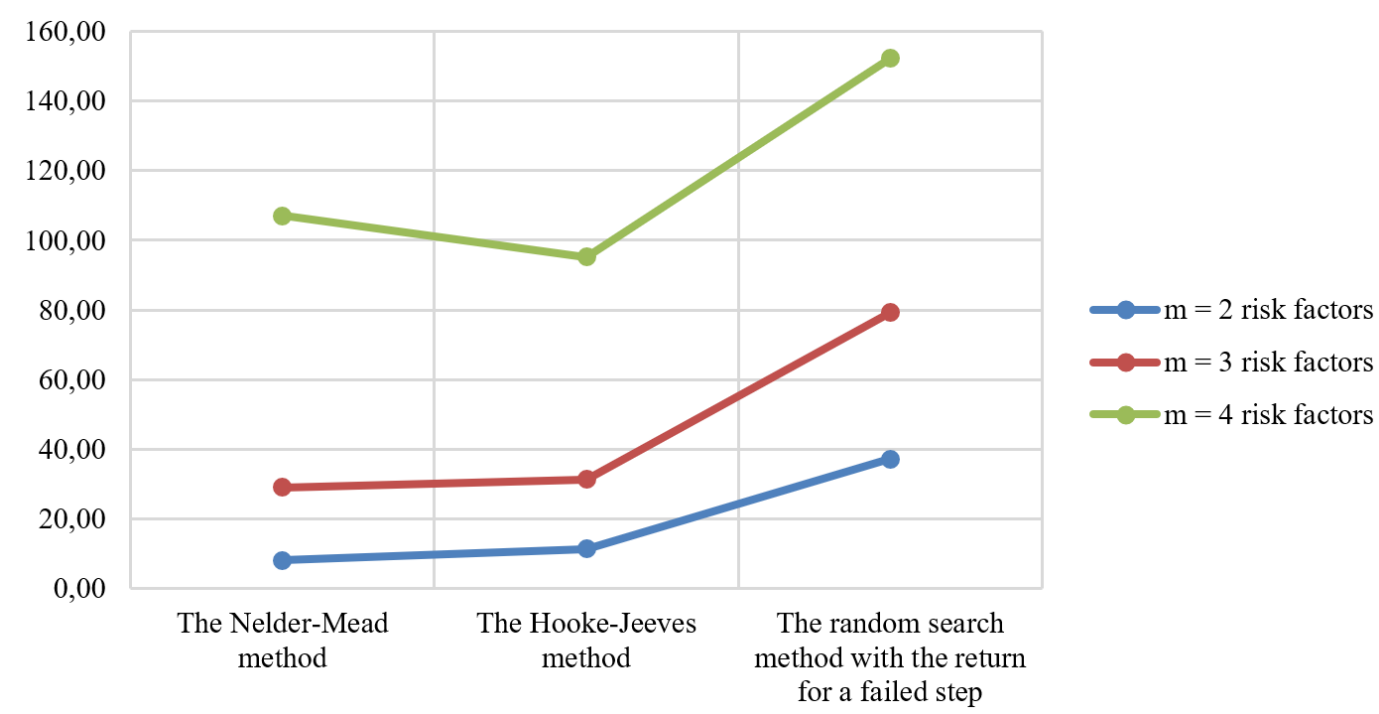

Fig. 6. Average calculation time for different number of risk factors.

acceptable risk level with minimal changes in numerical characteristics by gradient descent method for unconstrained minimization.

The support function will be:

$$
\begin{aligned}
& F\left(\boldsymbol{\Sigma}, \mathbf{a}, b_{k}\right)=\left(\sigma_{11}-\sigma_{11}^{0}\right)^{2}+\left(\sigma_{21}-\sigma_{21}^{0}\right)^{2}+\left(\sigma_{22}-\sigma_{22}^{0}\right)^{2}+\left(a_{1}-a_{1}^{0}\right)^{2}+\left(a_{2}-a_{2}^{0}\right)^{2}+ \\
& +b^{k} \cdot\left(\frac{1}{\sigma_{11}}+\frac{1}{\sigma_{22}}+\frac{1}{\sigma_{11} \sigma_{22}-\sigma_{12}{ }^{2}}+\frac{1}{\sigma_{11}^{-}-\sigma_{11}}+\frac{1}{\sigma_{22}^{-}-\sigma_{22}}+\frac{1}{\sigma_{12}^{-}-\sigma_{12}}+\frac{1}{\sigma_{11}-\sigma_{11}^{+}}+\frac{1}{\sigma_{22}-\sigma_{22}^{+}}+\frac{1}{\sigma_{12}-\sigma_{12}^{+}}+\right. \\
& \left.+\frac{1}{a_{1}^{-}-a_{1}}+\frac{1}{a_{2}^{-}-a_{2}}+\frac{1}{a_{1}-a_{1}^{+}}+\frac{1}{a_{2}-a_{2}^{+}}\right) .
\end{aligned}
$$

To find the minimum point of function $F\left(\boldsymbol{\Sigma}, \mathbf{a}, b_{k}\right)$ by the gradient descent method, it is necessary to find all the partial derivatives of the helper function:

$$
\begin{gathered}
\frac{\partial F\left(\boldsymbol{\Sigma}, \mathbf{a}, b_{k}\right)}{\partial \sigma_{11}}=-2 \cdot\left(\sigma_{11}-\sigma_{11}^{0}\right)+b^{k} \cdot\left(\frac{-1}{\sigma_{11}^{2}}+\frac{-\sigma_{22}}{\left(\sigma_{11} \sigma_{22}-\sigma_{12}\right)^{2}}+\frac{1}{\left(\sigma_{11}^{-}-\sigma_{11}\right)^{2}}+\frac{-1}{\left(\sigma_{11}-\sigma_{11}^{+}\right)^{2}}\right) ; \\
\frac{\partial F\left(\boldsymbol{\Sigma}, \mathbf{a}, b_{k}\right)}{\partial \sigma_{12}}=-2 \cdot\left(\sigma_{12}-\sigma_{12}^{0}\right)+b^{k} \cdot\left(\frac{2 \sigma_{12}}{\left(\sigma_{11} \sigma_{22}-\sigma_{12}\right)^{2}}+\frac{1}{\left(\sigma_{21}^{-}-\sigma_{21}\right)^{2}}+\frac{-1}{\left(\sigma_{21}-\sigma_{21}^{+}\right)^{2}}\right) ; \\
\frac{\partial F\left(\boldsymbol{\Sigma}, \mathbf{a}, b_{k}\right)}{\partial \sigma_{22}}=-2 \cdot\left(\sigma_{22}-\sigma_{22}^{0}\right)+b^{k} \cdot\left(\frac{-1}{\sigma_{22}^{2}}+\frac{-\sigma_{11}}{\left(\sigma_{11} \sigma_{22}-\sigma_{12}\right)^{2}}+\frac{1}{\left(\sigma_{22}^{-}-\sigma_{22}\right)^{2}}+\frac{-1}{\left(\sigma_{22}-\sigma_{22}^{+}\right)^{2}}\right) ; \\
\frac{\partial F\left(\boldsymbol{\Sigma}, \mathbf{a}, b_{k}\right)}{\partial a_{1}}=-2 \cdot\left(a_{1}-a_{1}^{0}\right)+b^{k} \cdot\left(\frac{1}{\left(a_{1}^{-}-a_{1}\right)^{2}}+\frac{-1}{\left(a_{1}-a_{1}^{+}\right)^{2}}\right) ; \\
\frac{\partial F\left(\boldsymbol{\Sigma}, \mathbf{a}, b_{k}\right)}{\partial a_{2}}=-2 \cdot\left(a_{2}-a_{2}^{0}\right)+b^{k} \cdot\left(\frac{1}{\left(a_{2}^{-}-a_{2}\right)^{2}}+\frac{-1}{\left(a_{2}-a_{2}^{+}\right)^{2}}\right) .
\end{gathered}
$$

The gradient of the support function has the form:

$$
\nabla F\left(\boldsymbol{\Sigma}, \mathbf{a}, b_{k}\right)=\left(\frac{\partial F\left(\boldsymbol{\Sigma}, \mathbf{a}, b_{k}\right)}{\partial \sigma_{11}} ; \frac{\partial F\left(\boldsymbol{\Sigma}, \mathbf{a}, b_{k}\right)}{\partial \sigma_{12}} ; \frac{\partial F\left(\boldsymbol{\Sigma}, \mathbf{a}, b_{k}\right)}{\partial \sigma_{22}} ; \frac{\partial F\left(\boldsymbol{\Sigma}, \mathbf{a}, b_{k}\right)}{\partial a_{1}} ; \frac{\partial F\left(\boldsymbol{\Sigma}, \mathbf{a}, b_{k}\right)}{\partial a_{2}}\right) .
$$


Then the gradient norm will be calculated using the formula:

$$
\begin{aligned}
& \left|\nabla F\left(\boldsymbol{\Sigma}, \mathbf{a}, b_{k}\right)\right|= \\
& =\sqrt{\left(\frac{\partial F\left(\boldsymbol{\Sigma}, \mathbf{a}, b_{k}\right)}{\partial \sigma_{11}}\right)^{2}+\left(\frac{\partial F\left(\boldsymbol{\Sigma}, \mathbf{a}, b_{k}\right)}{\partial \sigma_{12}}\right)^{2}+\left(\frac{\partial F\left(\boldsymbol{\Sigma}, \mathbf{a}, b_{k}\right)}{\partial \sigma_{22}}\right)^{2}+\left(\frac{\partial F\left(\boldsymbol{\Sigma}, \mathbf{a}, b_{k}\right)}{\partial a_{1}}\right)^{2}+\left(\frac{\partial F\left(\boldsymbol{\Sigma}, \mathbf{a}, b_{k}\right)}{\partial a_{2}}\right)^{2}} .
\end{aligned}
$$

For second-order methods (for example, Newton's method), it is necessary to find second derivatives, that is, the complexity will increase significantly

Let's see how the number of variables and restrictions depends on the number of risk factors (see Table 3).

Table 3

Dependence of the number of variables and restrictions on the number of risk factors

\begin{tabular}{|c|c|c|l|l|l|}
\hline \multirow{2}{*}{$\mathrm{m}$} & \multirow{2}{*}{$\begin{array}{l}\text { Number } \\
\text { of } \\
\text { variables }\end{array}$} & $\begin{array}{l}\text { Number } \\
\text { of } \\
\text { restrictions }\end{array}$ & $\begin{array}{l}\text { Zero-order } \\
\text { methods }\end{array}$ & $\begin{array}{l}\text { First-order } \\
\text { methods }\end{array}$ & $\begin{array}{l}\text { Second-order } \\
\text { methods }\end{array}$ \\
\hline 2 & 5 & 13 & $\frac{m^{2}+m}{2}+m$ & $\left(\frac{m^{2}+m}{2}+m\right)^{2}$ & $\left(\frac{m^{2}+m}{2}+m\right)^{4}$ \\
\hline 3 & 9 & 24 & $\frac{m^{2}+m}{2}+m$ & $\left(\frac{m^{2}+m}{2}+m\right)^{2}$ & $\left(\frac{m^{2}+m}{2}+m\right)^{4}$ \\
\hline 4 & 14 & 38 & $\frac{m^{2}+m}{2}+m$ & $\left(\frac{m^{2}+m}{2}+m\right)^{2}$ & $\left(\frac{m^{2}+m}{2}+m\right)^{4}$ \\
\hline 5 & 20 & 55 & $\frac{m^{2}+m}{2}+m$ & $\left(\frac{m^{2}+m}{2}+m\right)^{2}$ & $\left(\frac{m^{2}+m}{2}+m\right)^{4}$ \\
\hline
\end{tabular}

As can be seen from Table 3, the computational complexity of zero-order methods grows at a quadratic rate. At the same time, methods of the first and second-order, due to their peculiarities, require $O\left(m^{4}\right)$ and $O\left(m^{6}\right)$ complexity.

\section{Conclusions}

1. Various methods of optimizing the risk management problem of multidimensional Gaussian systems were considered. At the same time, all features of a problem (1) are considered: stochastic restriction for the required risk level, non-convexity of area of admissible decisions and growth of number of the managing variables in a problem of achieving an acceptable level of risk $r^{*}$ with minimal changes in the numerical characteristics $\boldsymbol{\Sigma}$ and a of the Gaussian system with a square speed of $m(m+3) / 2$.

2 . The research showed that the first- and second-order methods do not always lead to the result, they are not sufficiently effective due to the non-convexity of the area of admissible decisions and the labor intensity increases significantly with the increase in the number of risk factors.

3. Of the zero-order methods, the most effective was a modification of the NelderMead method. It finds a solution with comparable labor intensity to other methods, quite accurately.

\section{References}

1. Akimov V. A., Lesnykh V. V., Radaev N. N. Risks in the Nature, Technosphere, Society and the Economy. Moscow, Business Express, 2004. (in Russian) 
2. Vishnyakov Ya. D., Radayev N. N. General Theory of Risks.. Moscow, Academiya publ., 2007. (in Russian)

3. Mun J. Modeling Risk: Applying Monte Carlo Risk Simulation, Strategic Real Options, Stochastic Forecasting, and Portfolio Optimization. Hoboken: John Wiley \& Sons, 2010.

4. Rösch D., Scheule H. Model Risk - Identification, Measurement and Management. London, Risk Books, 2010.

5. Madera A. G. [Risks and Chances: Uncertainty, Forecasting and Estimation]. Moscow, Krasand Publ., 2014. (in Russian)

6. Solojentsev E. D. Scenario Logic and Probabilistic Management of Risk in Business and Engineering. Springer US, 2009. DOI: 10.1007/978-0-387-77946-1

7. Ryabinin I. A. [Relibility and Safety of Structure-Complex Systems]. St. Petersburg, Politechnika Publ., 2000. (in Russian)

8. Vorob'yov Yu. L., Malinetskii G. G., Makhutov N. A. Risk Management and Sustainable Development. Humanitarian Dimension. Izvestiya VUZ. Applied Nonlinear Dynamics, 2000, vol. 8, no. 6, pp. 12-26. (in Russian)

9. Tyrsin A. N. [About Risk Modeling in Critical Infrastructure Systems]. [Economic and Technical Aspects of Safety of Construction Critical Infrastructures: Materials of the International Conference. Yekaterinburg, Russia, 10-11.06.2015]. Yekaterinburg, Ural Federal University Publ., 2015, pp. 205-208.

10. Tyrsin A. N., Surina A. A. Modeling of Risk in Multidimensional Stochastic Systems. Tomsk State University Journal of Control and Computer Science, 2017, no. 39, pp. 6572. DOI: $10.17223 / 19988605 / 39 / 9$. (in Russian)

11. Surina A. A., Tyrsin A. N. Risk Management in Gaussian Stochastic Systems as an Optimization Problem. Mathematical Optimization Theory and Operations Research - 18th International Conference, MOTOR 2019, Revised Selected Papers (Communications in Computer and Information Science). Springer, 2019, vol. 1090 CCIS, pp. 562-577. DOI: 10.1007/978-3-030-33394-2_43

12. Panteleev A. V., Letova T. A. Optimization Methods in Examples and Tasks. Moscow, Vysshaya shkola Publ., 2008. (in Russian)

13. Gill P., Murray W. Numerical Methods for Constrained Optimization. London, Academic Press, 1974.

14. Mikhaylov G. A., Voytishek A. V. Numerical Statistical Modeling. Monte Carlo Methods. Moscow, Academiya publ., 2006. (in Russian)

15. Vasilyev F. P. [Numerical Methods of Solving Extremal Problems]. Moscow, Nauka Publ., 1988. (in Russian)

Alfiya A. Surina, Postgraduate Student, Department of Applied Mathematics and Programming, South Ural State University (Chelyabinsk, Russian Federation), surinaaa@susu.ru.

Received August 3, 2020. 


\title{
ОПТИМИЗАЦИОННЫЕ АЛГОРИТМЫ УПРАВЛЕНИЯ РИСКОМ В МНОГОМЕРНЫХ ГАУССОВСКИХ СИСТЕМАХ
}

\section{A. A. Сурина}

\begin{abstract}
В статье представлен сравнительный анализ оптимизационных алгоритмов для решения задачи управления риском в гауссовских стохастических системах. Оптимизационная задача, рассматриваемая в работе, имеет ряд особенностей, которые необходимо учитывать при решении. Особенностями задачи являются наличие стохастического ограничения на требуемый уровень риска, невыпуклость области допустимых решений и рост числа управляющих переменных в задаче достижения приемлемого уровня риска. Предложены пути решения проблемы возникновения множества локальных минимумов. Проведено исследование эффективности методов нулевого, первого и второго порядков для решения задачи безусловной минимизации с помощью метода статистических испытаний Монте-Карло. Каждый метод был адаптирован под особенности решаемой задачи. Выполнена программная реализация всех представленных алгоритмов. В статье представлены результаты исследования. Рассчитана вычислительная сложность алгоритмов.

Ключевые слова: модель; риск; управление; стохастическая система; алгоритм; мониторинг; оптимизация.
\end{abstract}

\section{Литература}

1. Акимов, В. А. Риски в природе, техносфере, обществе и экономике / В. А. Акимов, В. В. Лесных, Н. Н. Радаев. - Москва: Деловой экспресс, 2004.

2. Вишняков, Я. Д. Общая теория рисков / Я. Д. Вишняков, Н. Н. Радаев. - Москва: Академия, 2007.

3. Mun, J. Modeling Risk: Applying Monte Carlo Risk Simulation, Strategic Real Options, Stochastic Forecasting, and Portfolio Optimization / J. Mun. - Hoboken: John Wiley \& Sons, 2010.

4. Rösch, D. Model Risk - Identification, Measurement and Management / D. Rösch, H. Scheule. - London: Risk Books, 2010.

5. Мадера, А .Г. Риски и шансы: неопределенность, прогнозирование и оценка А. Г. Мадера. - Москва: Красанд, 2014.

6. Соложенцев Е. Д. Сценарное логико-вероятностное управление риском в бизнесе и технике / Е. Д. Соложенцев. - СПб: Бизнес-пресса, 2004.

7. Рябинин, И. А. Надежность и безопасность структурно-сложных систем И. А. Рябинин. - СПб: Политехника, 2000.

8. Воробьев, Ю. Л. Управление риском и устойчивое развитие: человеческое измерение / Ю. Л. Воробьев, Г. Г. Малинецкий, Н. А. Махутов // Известия вузов. Прикладная нелинейная динамика. - 2000. - Т. 8, № 6. - С. 12-26.

9. Тырсин, А. Н. О моделировании риска в системах критичных инфраструктур / А. Н. Тырсин // Экономические и технические аспекты безопасности строительных критичных инфраструктур: материалы международной конференции. Екатеринбург, РФ, 10-11.06.2015. - Екатеринбург: УрФУ, 2015. - С. 205-208. 
10. Тырсин, А. Н. Моделирование риска в многомерных стохастических системах А. Н. Тырсин, А. А. Сурина // Вестник Томского государственного университета. Управление, вычислительная техника и информатика. - 2017. - № 39. - С. 65-72.

11. Surina, A. A. Risk Management in Gaussian Stochastic Systems as an Optimization Problem / A. A. Surina, A. N. Tyrsin // Mathematical Optimization Theory and Operations Research - 18th International Conference, MOTOR 2019, Revised Selected Papers (Communications in Computer and Information Science). - Springer, 2019. V. 1090 CCIS, P. 562-577.

12. Пантелеев, А. В. Методы оптимизации в примерах и задачах / А. В. Пантелеев, Т. А. Летова. - М.: Высшая школа, 2008.

13. Gill, P. Numerical Methods for Constrained Optimization / P. Gill, W. Murrey. London: Academic press, 1974.

14. Михайлов, Г. А. Численное статистическое моделирование. Методы МонтеКарло / Г. А. Михайлов, А. В. Войтишек. - М.: Академия, 2006.

15. Васильев, Ф. П. Численные методы решения экстремальных задач: учеб. пособие для вузов / Ф. П. Васильев. - М.: Наука, 1988.

Сурина Альфия Адгамовна, аспирант, кафедра прикладной математики и программирования, Южно-Уральский государственный университет (г. Челябинск, Российская Федерачия), surinaаa@susu.ru.

Поступила в редакиию 3 августа 2020 г. 